\title{
Destination Branding Indonesia sebagai Destinasi Wisata Halal
}

\author{
Alwafi Ridho Subarkah ${ }^{*}$, Junita Budi Rachman², Akim³ \\ Universitas Padjadjaran, Indonesia ${ }^{123}$ \\ Email: alwafisubarkah@gmail.com ${ }^{1}$,junita@unpad.ac.id ${ }^{2}$, akim@unpad.ac.id ${ }^{3}$
}

\begin{abstract}
This study aims to discuss the destination branding of Indonesia using halal tourism instruments to increase tourist arrivals, especially from the Middle East market, and make Indonesia the world's halal tourist destination. This research uses descriptive qualitative method with the concept of destination branding and public diplomacy. The results of this study indicate that Indonesia embarked on destination branding by establishing the Halal Tourism Indonesia Logo, Halal Tourism Indonesia: The Halal Wonders, to describe its halal tourist destinations, then designating three regions that are considered ready to be the leading halal tourist destinations, namely Lombok (Friendly Lombok), Aceh (The Light of Aceh), and West Sumatra (Taste of Padang) as seen from facilities and services that meet the criteria halal tourism and won the world's best halal tourism award representing Indonesia at the World Halal Travel Summit in Abu Dhabi 2015 and 2016. In addition, Indonesia also made efforts to halal tourism diplomacy through familiarization trips, attending national and international exhibitions, and through the media and seen the results of the increasing number of Middle Eastern tourists visiting as the primary target market for halal tourism.
\end{abstract}

Keywords: Halal Tourism; Destination Branding; Public Diplomacy.

\begin{abstract}
Abstrak
Penelitian ini bertujuan untuk membahas destination branding Indonesia menggunakan instrumen pariwisata halal untuk meningkatkan kunjungan wisatawan terutama dari pasar Timur Tengah dan menjadikan Indonesia sebagai destinasi wisata halal dunia. Penelitian ini menggunakan metode kualitatif deskriptif dengan konsep destination branding dan diplomasi publik. Hasil penelitian ini menunjukkan bahwa Indonesia melakukan destination branding dengan menetapkan Logo Halal Tourism Indonesia, Halal Tourism Indonesia: The Halal Wonders, untuk menggambarkan destinasi wisata halalnya, kemudian menunjuk tiga daerah yang diangap siap menjadi destinasi wisata halal unggulan, yakni Lombok (Friendly Lombok), Aceh (The Light of Aceh), dan Sumatera Barat (Taste of Padang) yang dilihat dari fasilitas dan layanan memenuhi kriteria dan mendapatkan penghargaan wisata halal terbaik dunia mewakili Indonesia pada jang World Halal Travel Summit di Abu Dhabi 2015 dan 2016. Selain itu, Indonesia juga melakukan upaya diplomasi pariwisata halal melalui familiarization trips, mengikuti pameran nasional dan internasional, serta melalui media dan terlihat hasilnya dari meningkatnya jumlah kunjungan wisatawan Timur Tengah sebagai target pasar utama wisata halal.
\end{abstract}

Kata Kunci: wisata halal; destination branding; diplomasi public.

\section{A. PENDAHULUAN}

Pariwisata halal mengalami peningkatan yang signifikan setiap tahunnya. Terlihat dari jumlah perjalanan wisatawan Muslim yang terus tumbuh dari tahun 2014 hingga 2019. Berdasarkan data dari Global Muslim Travel Index, pada tahun 2014 ada 108 juta wisatawan Muslim yang berwisata (MasterCard \& CrescentRating, 2015:4); Tahun 2015 meningkat menjadi 117 juta wisatawan Muslim (MasterCard; CrescentRating, 2016:4); Tahun 2016 mencapai 121 juta wisatawan Muslim (Mastercard \& CrescentRating, 2017:3); Tahun 2017 mencapai 131 juta wisatawan Muslim (Mastercard \& CrescentRating, 2018:3); dan tahun 2018 meningkat hingga 140 juta wisatawan Muslim, proyeksinya pada tahun 2020 akan menjadi 160 juta wisatawan Muslim dengan pengeluaran hingga USD 40 Miliar dan pada tahun 2026 hingga 230 juta wisatawan Muslim dengan pengeluaran mencapai USD 300 Miliar

* Corresponding author

Received: May 10, 2020; Revised: May 29, 2020; Accepted: May 30, 2020 
(MasterCard \& CrescentRating, 2019:18). Tren ini menjadi pangsa pasar potensial bagi negara-negara yang mau mengembangkan sektor wisata halal.

Negara yang tinggi kunjungan wisatawan Muslim pada tahun 2018 yaitu Turki kedatangan 6,4 juta wisatawan, lalu Uni Emirat Arab 6,2 juta wisatawan, Rusia 5,6 juta wisatawan, Prancis 5 juta wisatawan, Malaysia 4,8 juta wisatawan. Sedangkan pengeluaran paling banyak pada tahun 2018 yaitu wisatawan asal Arab Saudi sebesar USD 22 Miliar, Uni Emirat Arab USD 17 Miliar, Qatar USD 15 Miliar, Kuwait USD 12 Miliar, Indonesia USD 11 Miliar, Iran USD 8 Miliar, Malaysia USD 8 Miliar, Rusia USD 8 Miliar, Nigeria USD 7 Miliar, dan Prancis USD 5 Miliar (ThomsonReuters and DinarStandard, 2019:77). Terlihat yang menarik di sini adalah wisatawan Muslim memilih Rusia dan Prancis sebagai salah satu negara yang banyak dikunjungi, padahal kedua negara tersebut Muslim sebagai minoritas.

Indonesia merupakan negara mayoritas penduduknya Muslim mestinya menjadi salah satu negara yang paling banyak dikunjungi wisatawan Muslim. Pada tahun 2015 berdasarkan data dari Pew Research Center menunjukkan bahwa populasi Muslim di Indonesia menjadi yang terbesar sebanyak 219,960,000 atau setara 87,1 persen penduduk Indonesia Muslim, setara dengan 12,6 persen dari populasi Muslim dunia (Pew Research Center, 2019). Selain itu destinasi wisata di Indonesia banyak pilihan dan beragam, seperti Sumatera Barat, Lombok, dan Aceh yang menjadi destinasi wisata halal unggulan (Kementerian Pariwisata RI, 2016). Jika dibandingkan dengan Rusia maupun Prancis yang populasi Muslimnya sedikit, serta kebergaman wisata di Indonesia harusnya mampu menarik wisatawan lebih banyak lagi.

Jika dibandingkan dengan negara lain di ASEAN, Indonesia menduduki peringkat ke empat berdasarkan jumlah kunjungan wisatawan sebesar 15 juta wisatawan, posisi ketiga Singapura sebesar 18 juta wisatawan, kedua Malaysia 25 juta wisatawan, dan Thailand paling banyak sebesar 38 juta wisatawan (Katadata.co.id, 2019). Sedangkan untuk kunjungan wisatawan Muslim ke Indonesia hanya 1,19 juta wisatawan, jauh tertinggal dengan Malaysia sebesar 4,86 juta wisatawan Muslim, bahkan lebih rendah kunjungan wisatawan Muslim Indonesia jika dibandingkan dengan Thailand sebesar 2,60 juta wisatawan meski mayoritas masyarakatnya non-Muslim (Organisasi Kerjasama Islam, 2016).

Sebagai upaya untuk meningkatkan kunjungan pariwisata ke Indonesia ditambahkan segmen baru bernama wisata halal ini untuk menarik kunjungan wisatawan Muslim. Maka dari itu, Indonesia membidik wisatawan Timur Tengah karena pengeluaran untuk berwisata di Indonesia sebesar USD 1.750 hingga USD 2.000 per kunjungan yang mana lebih besar dari wisatawan mancanegara secara keseluruhan hanya USD 1.200 per kunjungan atau lebih rendah 46 hingga 67 persen (Tempo.co, 2017).

Ada berbagai penelitian terdahulu yang membahas tentang perkembangan pariwisata halal di Indonesia, seperti penelitian dari (Destiana \& Astuti, 2019) judul penelitian Pengembangan Pariwisata Halal di Indonesia dengan hasil penelitian menunjukkan bahwa pembangunan untuk pariwisata halal sudah mulai dibangun di beberapa daerah, namun perlu ditingkatkan beberapa hal seperti terkait regulasi, pentingnya kesadaran sertifikasi halal, dan mengembangkan sumber daya manusia yang berdaya saing. Penelitian kedua dari (Millatina, et al., 2019) menjelaskan bahwa dalam pemerintah Indonesia mengembangkan pariwisata halal melalui pengembangan fasilitas utama, perencanaan daerah yang menjadi area destinasi wisata dan segala infrastrukturnya, membuat kebijakan dan membuat regulasi yang mengatur penyelenggaraan pariwisata halal.

Penelitian ketiga dari (Aziz \& Athoillah, 2019) menyatakan bahwa pariwisata halal dapat menjadi pembangunan ekonomi karena tren wisata halal terus mengalami peningkatan dan potensinya yang besar dapat menjadi alternatif pembangunan ekonomi. Penelitian keempat dari (Wahyono, et al., 2019) bahwa pariwisata halal dapat menjadi daya saing suatu bangsa dengan melakukan pemenuhan atribut fasilitas dan layanan ramah keluarga, serta kesadaran terkait halal. Penelitian kelima dari (Genoveva \& 
Muhammad, 2019) Jakarta memiliki potensi yang juga cukup bagus dalam mengembangkan pariwisata halal dengan melakukan city branding.

Penelitian keenam dari (Pratama, et al., 2019) hasil penelitiannya menunjukkan bahwa melalui kebijakan publik dan branding dalam upaya pariwisata, Sumatera Barat berhasil meyakinkan wisatawan bahwa provinsi ini ramah terhadap turis muslim melalui berbagai aturan dan insentif terhadap pemegang saham yang bertanggung jawab untuk mempromosikan upaya pariwisata halal. Juga, sebagai provinsi yang sebagian besar penduduknya beragama Islam, upaya branding Sumatera Barat berhasil menunjukkan bahwa agama dan budaya dapat berjalan seiring. Penelitian ketujuh dari (Widhasti, Damayanti, \& Sardjono, 2017) yang melihat wisata halal Indonesia menjadi soft power dengan melakukan diplomasi publik untuk menarik wisatawan Muslim dengan cara menampilkan nilai-nilai Islam yang ada di Indonesia secara keseluruhan pada lingkup nasional.

Sedangkan penelitian ini lebih melihat kepada destination branding yang dilakukan oleh Indonesia dalam mengembangkan pariwisata halal di tiga daerah yang menjadi destinasi wisata halal prioritas yakni Aceh, Sumatera Barat dan Lombok yang melihat pariwisata halal sebagai instrumen diplomasi publik Indonesia untuk menarik kunjungan wisatawan Muslim.

\section{B. TINJAUAN PUSTAKA}

\section{Konsep Wisata Halal}

Istilah halal ada dalam agama Islam yang berarti sesuatu yang diperbolehkan untuk dilakukan, digunakan, serta diusahakan berdasarkan syariat Islam (Ali, 2016). Terminologi halal sering ditemukan pada makanan dan minuman, yaitu sesuatu yang diperbolehkan untuk dikonsumsi oleh orang Muslim, Food and Agriculture Organization of the United Nations (FAO) memiliki The Codex Alimentarius Commission General Guidelines for Use of The Term "Halal" (CAC/GL 24-1997) mengatur penggunaan istilah halal (Food Agriculture Organization, 1997). Halal berarti sesuatu yang diperbolehkan menurut ajaran Agama Islam.

Terminologi halal saat ini juga digunakan pada sektor pariwisata yaitu upaya untuk memberikan fasilitas dan layanan bagi wisatawan Muslim sesuai dengan syariat dan prinsip-prinsip Islam yang dikenal dengan istilah wisata halal. Organisasi Kerja sama Islam (OKI) memperkenalkan istilah wisata halal lainnya seperti Islamic Tourism, Muslim-Friendly Tourism, Halal Travel, Halal Hospitality (Organisasi Kerjasama Islam, 2016), yang memiliki komponen hotel, makanan, transportasi (udara), paket wisata halal, dan keuangan harus sesuai dengan ajaran Islam (Organisasi Kerjasama Islam, 2017). Sedangkan (Hall, Razak, \& Prayag, 2020) menggunakan istilah halal hospitality dan Islamic tourism merupakan dua hal yang sama dengan tujuan memberi kenyamanan bagi wisatawan Muslim.

Berdasarkan Global Islamic Economy Report menjelaskan wisata halal merupakan upaya menjalankan nilai-nilai Islam tanpa mengurangi unsur hiburan yang diinginkan wisatawan Muslim (Dinar Standard, 2019). Adapun kriteria utama wisata halal yaitu melihat lingkungan, akses, dan layanan dengan indikator: tersedianya makanan halal, tempat solat yang memadai, tersedia air bersih di toilet, tidak ada isu islamophobia, ada layanan saat Ramadhan, pengalaman tentang Islam di area wisata, terpisahnya laki-laki dan perempuan pada fasilitas umum seperti kolam renang, tempat olah raga, serta tidak terdapat aktivitas non-halal (Global Muslim Travel Index, 2019).

Dalam konteks penelitian ini ingin melihat wisata halal Indonesia sebagai negara yang mayoritas Islam menyediakan fasilitas dan layanan untuk wisatawan Muslim, mulai dari makanan dan minuman halal serta destinasi wisata halal yang layak dikunjungi seperti Lombok, Sumatera Barat, dan Aceh. 


\section{Destinasi Branding dan Diplomasi Publik}

Sebagai upaya mengemas potensi wisata halal Indonesia digunakan pendekatan destination branding, yaitu sesuatu tampilan dalam bentuk nama, simbol, logo, slogan, atau gambar yang dapat mencirikan destinasi dan membedakan dari destinasi lainnya yang menjadi daya tarik sehingga mudah diingat oleh pengunjung dan merasakan pengalaman berbeda di tempat wisata tersebut secara emosional (Ritchie \& Ritchie, 1998:103). Ini merupakan turunan dari konsep nation branding yang mengedepankan citra melalui tampilan untuk menarik perhatian publik.

Menurut Buhalis destination branding yaitu terkait dengan wilayah geografis tertentu yang dipahami oleh wisatawan sebagai entitas yang unik, dengan kerangka politik dan legislatif dalam rangka pemasaran dan perencanaan pariwisata (Dimitrios, 2000:1-2). Sedangkan Cai, destination branding yaitu membangun citra positif dengan menggabungkan hal-hal yang unik dari suatu tempat (Cai, 2002:721723). Berarti bahwa destination branding sebagai langkah membangun citra positif negara dan memasarkan pariwisata.

Sehingga, destination branding merupakan upaya untuk menciptakan citra yang positif tentang suatu daerah tujuan wisata dengan tujuan untuk menarik kunjungan wisatawan, serta memberikan pengalaman yang berkesan bagi pengunjung. Destination branding ini diperlukan agar persepsi antara pengelola tempat dan pengunjung memilki pemahaman yang sama tentang tujuan wisata.

Destination branding ini terdiri dari dua unsur, yakni Brand identity adalah cara suatu negara dalam menciptakan citranya dengan menampilkan secara keseluruhan atau sebagian dari pariwisata seperti alam, budaya, masyarakat, atau apapun yang dapat ditampilkan ke pada publik. Brand image yaitu persepsi penerima pesan terhadap destinasi wisata atau terhadap brand yang ditampilkan (BĂLTESCU et al., 2011). Dalam penelitian ini lebih membahas tentang brand identity suatu negara, sedangkan brand image dilakukan melalui diplomasi publik karena sifatnya ke luar negeri.

Adapun unsur dari Brand identity menurut yaitu: budaya, karakter, personalitas, nama, logo, dan slogan. Hal ini yang dapat mempengaruhi pandangan publik terhadap identitas suatu brand: Culture, tentang karakteristik budaya yang ada dalam masyarakat dan negara tersebut; Character sesuatu yang mencirikan negara tersebut, biasanya terdapat dalam peraturan atau konstitusi yang menjadi payung hukum dalam mendukung branding suatu negara; Personality, tentang kepribadian suatu masyarakat dalam menerima pengunjung yang datang; Name, seringkali adalah nama asli tujuan wisata, dalam bahasa domestik atau bahasa Inggris: ini merupakan hal penting, karena sangat terkait dengan strategi komunikasi yang menjadi target wisatawan, juga harus memiliki banyak kekuatan dan asosiasi yang unik, harus khas, dan mudah diingat; Logo, sesuatu yang dapat digambarkan hingga dapat mencakup karakteristik dari destinasi wisata dan harus simpel, mudah diingat, dapat merepresentasikan destinasi wisata tersebut; Slogan, dapat berupa kata-kata yang singkat dan padat untuk mencirikan destinasi wisata, dan dapat menarik kunjungan wisatawan (Risitano, 2006:7).

Penelitian ini menggunakan destination branding yang dilakukan Indonesia sebagai tujuan wisata halal dengan melihat pengembangan pariwisata halal di tiga daerah unggulan yaitu Lombok, Aceh, dan Sumatera Barat yang memiliki budaya, karakter, kepribadian, nama, logo dan slogan sesuai dengan kriteria konsep wisata halal, karena setiap daerah ini memiliki potensi wisata halal berdasarkan karakteristiknya masing-masing.

Sedangkan untuk mempromosikan wisata halal Indonesia menggunakan konsep wisata halal, menurut Melissen menjelaskan perbedaan antara diplomasi tradisional yaitu melibatkan perwakilan resmi untuk menjalin hubungan dengan negara lain, sedangkan diplomasi publik melibatkan aktor non negara atau publik dan sifat hubungan tidak resmi (Jan Melissen, 2005:3-4). Aktor dalam diplomasi publik berkembang, awalnya negara yang dominan, namun saat ini dapat dilakukan oleh aktor nonnegara, supranational, dan sub-negara dalam mendukung kebijakannya. Target diplomasi publik adalah 
publik asing dan publik domestik sendiri untuk menyatukan opini yang diinginkan oleh aktor tersebut. Penyampaian informasi bersifat positif dan dapat dilakukan satu arah maupun dua arah kepada publik asing sebagai penerima informasi utama (Jan Melissen, 2005:12-13).

Benny Susetyo menambahkan diplomasi publik ini dilakukan dalam rangka memenuhi kepentingan nasional dengan cara memberikan informasi, pemahaman, hingga mempengaruhi publik dalam menciptakan persepsi positif tentang suatu negara sehingga akan mudah untuk mencapai kesepakatan (Susetyo, 2008). Pada konteks ini mempengaruhi wisatawan Muslim untuk berkunjung ke Indonesia karena memiliki fasilitas dan layanan sesuai dengan kriteria wisata halal.

Sedangkan Menurut Mark Leonard, diplomasi publik dapat mencapai beberapa hal seperti meningkatkan pengetahuan dan apresiasi masyarakat terhadap negara; meningkatkan keterlibatan masyarakat; mempengaruhi masyarakat agar berinvestasi; masyarakat dapat memberikan dukungan kepada politisi atau pemerintah dalam mengambil kebijakan (Leonard et. al,, 2002:9-11). Diplomasi publik yang dilakukan negara dapat memberikan pemahaman tentang kebijakan yang diambil oleh pemerintah kepada masyarakat termasuk pengembangan wisata halal di daerah sebagai objek penelitian wisata halal Indonesia.

\section{METODE PENELITIAN}

Metode penelitian ini menggunakan metode kualitatif-deskriptif yang menggambarkan potensi pariwisata halal Indonesia yang kemudian dijadikan sebagai instrumen menarik kunjungan wisatawan Muslim dengan pendekatan destination branding sebagai upaya dalam mengemas potensi tersebut dan melakukan promosi dengan cara teknik diplomasi publik melalui acara internasional karena sasaran dari pemasaran wisata halal Indonesia yaitu wisatawan Muslim dunia dan lebih spesifik ke wisatawan asal Timur Tengah. Unit analisisnya branding wisata halal Indonesia dan tiga daerah yang menjadi destinasi wisata halal unggulan yakni Lombok, Aceh, dan Sumatera Barat, serta diplomasi publik yang dilakukan untuk mempromosikan wisata halal. Tiga daerah menjadi fokus penelitian karena memiliki kriteria yang mewakili Indonesia dalam pengembangan wisata halal dilihat dari fasilitas, layanan, dan peraturan daerah yang mendukung penyelenggaraan pariwisata halal, masing-masing daerah mendapat penghargaan internasional sebagai destinasi wisata halal terbaik dunia pada tahun 2015 dan 2016 dalam ajang World Halal Summit di Abu Dhabi. Pengumpulan data pada penelitian ini dengan studi pustaka yang bersumber dari buku, jurnal, laporan, berita resmi, press release sebagai sumber primer sedangkan sumber dari internet sebagai pendukung. Tahapan penelitian ini melalui pengumpulan data, penyajian data dalam bentuk narasi maupun gambar, dan menarik kesimpulan.

\section{HASIL DAN ANALISIS}

\section{Potensi Pariwisata Halal Indonesia}

Berdasarkan data Badan Pusat Statistik Indonesia tahun 2010, jumlah masyarakat Indonesia berjumlah 237.641.326 dan memeluk agama Islam mencapai 87,18 persen atau setara dengan 207.176.162 jiwa. (Badan Pusat Statistik Indonesia, 2010). Hal ini memudahkan pengelolaan wisata halal di Indonesia karena dapat fasilitas wisata halal yang dikembangkan juga sangat berdampak pada mayoritas penduduk Indonesia.

Makanan dan minuman halal yang menjadi kebutuhan wisatawan Muslim memiliki payung hukum di Indonesia dengan adanya Undang-Undang No. 33 Tahun 2014 Tentang Jaminan Produk Halal. Lembaga Pengkajian Pangan Obat-obatan dan Kosmetik Majelis Ulama Indonesia (LPPOM MUI) yang memiliki kewenangan sertifikasi halal untuk makanan, obat-obatan, kosmetik, restoran dan lain-lain mengeluarkan sertifikasi halal berdasarkan tabel 1 sejumlah 43.131 perusahaan yang mendapatkan 
sertifikasi halal, 51.945 sertifikasi halal yang dikeluarkan kepada 204.222 produk halal. Berikut uraian data yang dimaksud:

Table 1 Data Sertifikasi Halal

\begin{tabular}{cccc}
\hline Tahun & Jumlah Perusahaan & $\begin{array}{c}\text { Jumlah Seritifikasi } \\
\text { Halal }\end{array}$ & Jumlah Produk \\
\hline $\mathbf{2 0 1 4}$ & 10,180 & 10,322 & 68,576 \\
\hline $\mathbf{2 0 1 5}$ & 7,940 & 8,676 & 77,256 \\
\hline $\mathbf{2 0 1 6}$ & 6,564 & 7,392 & 114,264 \\
\hline $\mathbf{2 0 1 7}$ & 7,198 & 8,157 & 127,286 \\
\hline $\mathbf{2 0 1 8}$ & 11,249 & 17,398 & 204,222 \\
\hline Total & 43,131 & 51,945 & 591,604 \\
\hline
\end{tabular}

Sumber: (Majelis Ulama Indonesia, 2019b)

Majelis Ulama Indonesia juga mengembangkan sistem QR Code Scanner halal untuk restoran agar dapat mendeteksi keaslian dari sertifikasi halal di restoran tersebut dengan menampilkan nama restoran/outlet, pemegang sertifikat, masa berlaku, hingga nomor sertifikat karena sistem ini tersambung langsung dengan database dari Majelis Ulama Indonesia (MUI) (Majelis Ulama Indonesia, 2017). Hal ini tentu sangat memudahkan wisatawan Muslim.

Indonesia juga memiliki Halal Park di daerah Stadion Gelora Bung Karno, Jakarta. Kawasan ekosistem industri halal ini menjadi salah satu destinasi halal di Indonesia. Luas kawasan ini 21.000 meter persegi yang memiliki nilai investasi sebesar Rp. 250 Miliar, dalam kawasan ini menampilkan berbagai jenis produk halal mulai dari makanan dan minuman halal, fashion, dan yang lainnya.(Presiden RI, 2019). Kawasan halal ini berpotensi menarik kunjungan wisatawan Muslim.

Untuk fasilitas ibadah seperti masjid maupun mushalla di Indonesia tersebar di berbagai tempat. Berdasarkan Sistem Informasi Masjid (SIMAS) Direktorat Agama Islam dan Pembinaan Syariah, Direktorat Jenderal Bimas Islam, Kementerian Agama Islam Republik Indonesia terdapat 258.334 Masjid dan 295.626 Mushalla yang tersebar di berbagai daerah (Kementerian Agama RI, 2019c). Data masjid dan mushalla ini yang terdaftar di Kementerian Agama RI, ada banyak juga masjid dan mushalla yang belum terdaftar. Untuk memudahkan wisatawan Muslim, Dewan Masjid Indonesia mengembangkan aplikasi Dewan Masjid untuk mendeteksi masjid atau mushalla terdekat, menampilkan kegiatan pengurus masjid, da'i/mubalig, serta membantu Kementerian Agama RI dalam mendata masjid maupun mushalla (Dewan Masjid Indonesia, 2019).

Untuk destinasi wisata yang dapat dikunjungi wisatawan Muslim ke Indonesia diantaranya Lombok, Aceh, Sumatera Barat, Raiu dan Kepulauan Riau, Jawa Tengah, Malang Raya, Yogyakarta, Seulawesi Selatan dan Jawa Barat. (Kementerian Pariwisata RI, 2019a). Daerah ini dianggap memiliki potensi dari segi tempat wisatanya juga fasilitas dan layanan yang baik untuk wisatawan Muslim. Sesuai dengan konsep wisata halal yaitu pariwisata yang memberikan kenyamanan bagi wisatawan Muslim berdasarkan prinsip-prinsip dalam Islam. (MasterCard \& CrescentRating, 2016:7; Organisasi Kerjasama Islam, 2017:4). Pariwisata halal di Indonesia bukan berarti arabisasi, tetapi untuk fasilitasi wisatawan Muslim agar nyaman melakukan kegiatan wisata. (CNBC Indonesia, 2019). Tiga daerah yakni Lombok, Sumatera Barat dan Aceh menjadi daerah yang paling siap untuk mengembangkan konsep ini menjadi fokus dalam penelitian ini.

\section{Branding Destinasi Wisata Halal Indonesia}

Branding wisata halal Indonesia dapat dilihat logo, nama, dan slogan yang ditampilkan sebagai upaya untuk memberikan gambaran secara visual kepada masyarakat tentang pariwisata halal di 
Indonesia. Selain itu dalam branding destinasi juga membutuhkan budaya yang ada di masyarakat, karakteristik masyarakatnya yang mayoritas Muslim.

Untuk logo, slogan dan nama pariwisata halal di Indonesia yaitu "Halal Tourism Indonesia: The Halal Wonders" atau "Pariwisata Halal Indonesia: Yang Halal Menjadi Pesona" yang merupakan cobranding dari "Wonderful Indonesia" atau "Pesona Indonesia" dapat dilihat pada gambar 1. Berikut ini logo pariwisata halal Indonesia:

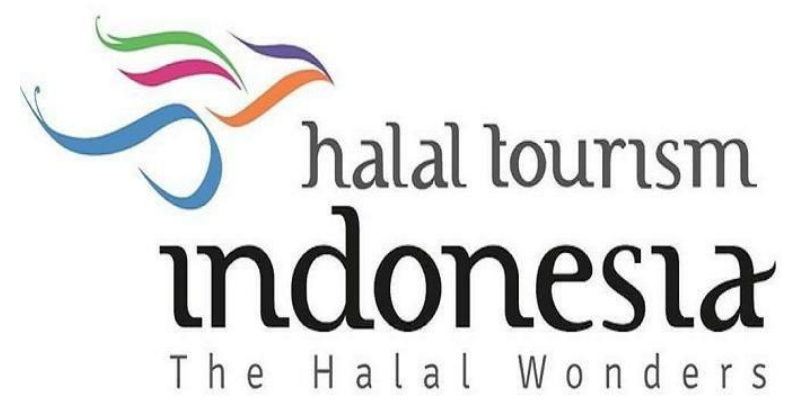

Gambar 1 Logo Pariwisata Halal Indonesia

Sumber: (Kementerian Pariwisata RI, 2018b)

Maksud dari logo pada gambar 1 adalah memperlihatkan Burung Garuda sebagai lambang negara, juga memberi makna sebagai burung yang suka berkelompok, menggunakan burung menjadi logo karena Indonesia memiliki banyak populasi burung. Rentang sayap tersebut memberi kesan keterbukaan, dan hasrat untuk terbang jauh. Bentuk burung yang sama dengan tulisan Arab pada logo ini sebagai lambang pariwisata halal. Setiap warna pada lambang burung ini memiliki warna tersendiri Biru (keterbukaan), Hijau (kreativitas, keselarasan dan ramah lingkungan), Jingga (keterbukaan, inovasi, perubahan), Ungu (kesatuan jiwa raga, iman, imajinasi), Magenta (pemikiran praktis, kepekaan dan keseimbangan)(Kementerian Pariwisata RI, 2018b).

Sedangkan untuk destinasi wisata halal unggulan yaitu tiga daerah seperti Sumatera Barat, Aceh, dan Lombok, Aceh pada gambar 2 memperlihatkan logo, nama, dan slogan yang berbeda untuk menggambarkan karakteristik pariwisatanya. Berikut gambar dari masing-masing daerah:
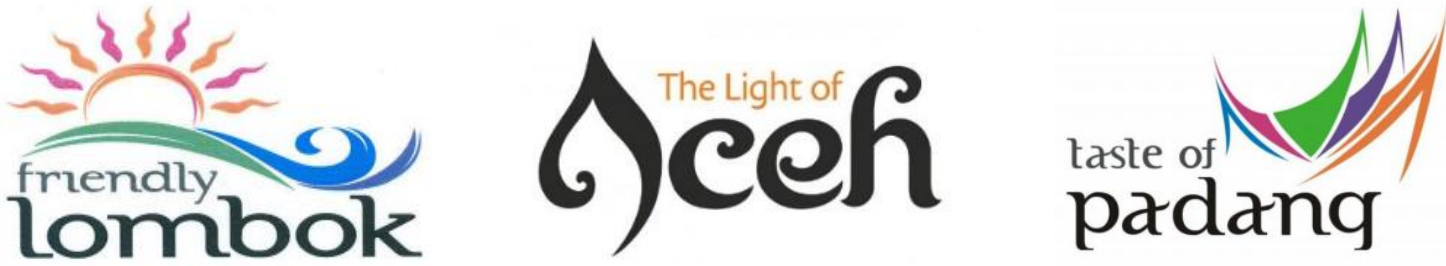

\author{
Gambar 2 Logo Pariwisata Halal Indonesia (Lombok, Aceh, Sumatera Barat)
}

Sumber: (Dinas Kebudayaan dan Pariwisata Aceh, 2016; Kementerian Pariwisata RI, 2018b; LombokPostTV, 2016; SK Gubernur Sumatera Barat, 2015)

Lombok menggunakan tagline "Friendly Lombok" untuk menunjukkan bahwa Lombok menerima semua wisatawan dengan ramah dan yang lebih spesifik lagi wisatawan Muslim (LombokPostTV, 2016). Aceh dengan "The Light of Aceh" bahwa Aceh dengan segala unsur Islam yang ada di dalamnya menjadi cahaya bagi semua wisatawan dengan prinsip Islam yang rahmatan lil alamin baik untuk semesta (Dinas Kebudayaan dan Pariwisata Aceh, 2016). Sedangkan Sumatera untuk menunjukkan ciri khasnya "Taste 
of Padang" dengan cita rasa makanan yang luar biasa ingin memberikan kesan luar biasa kepada wisatawan, namun tidak hanya menyentuh lidah wisatawan rasa yang dimaksudkan semua aspek pengalaman saat berkunjung di Sumatera Barat memberikan kesan tersendiri (SK Gubernur Sumatera Barat, 2015). Selanjutnya dijelaskan lebih rinci terkait branding dan pembangunan setiap daerah sebagai destinasi wisata halal.

\section{Branding Pariwisata Lombok}

Lombok merupakan destinasi wisata halal Indonesia yang paling baik dalam pengelolaannya. Pada tahun 2015 serta tahun 2016 mendapat penghargaan sebagai destinasi wisata halal terbaik dunia dan tempat honeymoon terbaik bagi wisatawan Muslim. Penghargaan ini diraih pada kegiatan World Halal Tourism Summit 2015 serta 2016 yang diselenggarakan di Abu Dhabi penghargaan tersebut: World's Best Halal Tourism Destination, World's Best Halal Honeymoon Destination, World's Best Halal Beach Resort, World's Best Halal Travel Website (CNN Indonesia, 2015; Kementerian Pariwisata RI, 2016)

Masyarakat Lombok yang mayoritas Muslim, pada tahun 2016 penduduk Islam sebesar 96,78 persen, yang kedua Hindu sebesar 2,45 persen; ketiga Budha 0,32 persen; keempat Kristen 0,26 persen; dan kelima Katolik 0,19 persen (BPS Provinsi NTB, 2017), Lombok sangat khas dengan karakteristik dan budaya Islam yang bersifat universal, sesuai dengan tagline "Friendly Lombok' untuk memberi rasa nyaman bagi semua wisatawan dan tentunya lebih khusus untuk wisatawan Muslim, misalnya untuk memberikan kenyamanan tempat ibadah yang tersebar di berbagai tempat untuk memudahkan wisatawan Muslim beribadah saat melakukan kegiatan wisata, terdapat 4.500 masjid berada di sekitar 598 Desa maupun di pusat perbelanjaan, dan sekitar tempat wisata. Destinasi wisata yang dapat dikunjungi wisatawan Muslim yaitu: Masjid Islamic center, Gili Nanggu, Desa Sade, Masjid Kuno Karang Bayan, Benang Kelambu, Gili Kedis, Sesaot, Gili Sudak (Subarkah, 2018:195).

Fasilitas untuk produk halal melalui Lembaga Pengkajian Pangan, Obat-Obatan, Kosmetik Majelis Ulama Indonesia Provinsi NTB telah memberi sertifikasi halal pada tahun 2015 ada 5 restoran hotel, sedangkan 2016 ada 75 restoran hotel. Pada tahun 2015 restoran bukan hotel sejumlah 75 yang terdata, mengalami peningkatan pada tahun 2016 sebesar 200 sertifikasi halal untuk restoran non-hotel. Sedangkan terdapat 75 seritifikasi halal untuk Usaha Mikro Kecil dan Menengah (UMKM) dan pada tahun 2016 meningkat menjadi 269 sertifikasi halal untuk UMKM (LPPOM MUI NTB, 2016). Lombok juga memiliki aturan terkait wisata halal dalam Peraturan Daerah No. 2 Tahun 2016 Tentang Penyelenggaraan Pariwisata Halal.

\section{Branding Pariwisata Nangroe Aceh Darussalam}

Aceh yang kental dengan nuansa Islam dikarenakan jumlah penduduk Islam yang besar memiliki nilai tersendiri. Islam sebesar 4,413,244 jiwa, sedangkan agam lain seperti Kristen 50,309 jiwa, lalu Katolik 3,315 jiwa, serta Hindu 136 jiwa, dan Budha 7,062 jiwa (Badan Pusat Statistik Indonesia, 2010:42). Terdapat 4085 masjid yang tersebar di kabupaten/kota Aceh (Kementerian Agama RI, 2019a). Sedangkan untuk produk halal pada tahun 2019 LPPOM Majelis Perumsyawaratan Ulama - Majelis Ulama Indonesia (LPPOM MPU MUI) mengeluarkan sertifikat halal untuk 307 makanan dan minuman halal, 7 restoran dan katering, 7 Rumah Potong Hewan. (LPPOM MPU ACEH, 2019). Maka dari itu branding Aceh dengan tagline "The Light of Aceh" dimaksudkan untuk memberikan pesan kepada wisatawan bahwa Aceh menjadi cahaya yang rahmatan lil alamin (Dinas Kebudayaan dan Pariwisata Aceh, 2016). Fasilitas dan layanan ini dapat memberi rasa nyaman bagi wisatawan Muslim karena kebutuhan saat berwisata dapat terpenuhi, mulai dari tempat ibadah hingga makanan dan minuman halal. Aceh memiliki Peraturan Walikota Banda Aceh No 17 tahun 2016 tentang Penyelenggaraan Wisata Halal 
Adapun tempat wisata yang dapat dikunjungi oleh wisatawan yaitu: Banda Ace dan Aceh Besar untuk segmen wisata budaya yang mencakup Museum Tsunami, Masjid Raya Baiturrahman, Pantai Lampuk, Selancar Angin, PLTD Apung, Selancar Layang, Pulau Tailana, Taman Sari Gunongan, Pulau Ulee Lheu, dan Museum Negeri Aceh. Sedangkan Sabang untuk wisata alam mencakup Tugu Kilometer 0, Pantai Iboih, dan Panatai Sumur Tiga. Aceh Jaya mencakup Arung Jeram Sungai Teunom,Teluk Rigaih, Pulau Tsunami, Gunung Geurutee dan Pasi Saka. Sedangkan di Dataran Tinggi Gayo memiliki konsep wisata budaya dan alam yang melingkupi Pantai Manye, Pantan Terong, Danau Laut Tawar, Wih Terjun, dan Gua Loyang Koro. Lalu di Singkil Pulau Banyak mengusung tema wisata alam snorkeling, Dermaga Singkil, Hopping Island, Pulau Panjang, Desa Ulo Saruk, Melelo,Rangit, Tailana, Palambak, Lambudung, Sikandang, dan Asok. (Travel.tempo.co, 2019). Tempat yang eksotis dari pantai hingga pegunungan memiliki daya tarik luar biasa untuk dikunjungi oleh wisatawan.

Aceh juga mendapat berbagai penghargaan di tingkat internasional pada tahun 2016 mendapat Anugerah Pariwisata Halal Terbaik pada kategori Bandara Ramah Wisatawan Terbaik, Daya Tarik Wisata Terbaik, Destinasi Budaya Ramah Wisatawan Muslim Terbaik, pada tahun yang sama di tingkat internasional juga meraih penghargaan di Abu Dhabi pada World Halal Tourism Award 2016 pada kategori World's Best Halal Cultural Destination, serta World's Best Airport for Halal Travelers. (Dinas Kebudayaan dan Pariwisata Aceh, 2018). Hal ini menunjukkan bahwa Aceh sangat layak untuk dikunjungi oleh wisatawan Muslim karena keseriusannya dalam mengembangkan pariwisata halal.

\section{Branding Pariwisata Sumatera Barat}

Karakteristik masyarakatnya yang juga mayoritas Islam sejumlah 4,721,924, Kristen 69,253, Katolik 40,428, Hindu 234, Budha 3,419 (Badan Pusat Statistik Indonesia, 2010). Masjid di Sumatera Barat sejumlah 4561 yang tersebar di kota/kabupaten baik itu Masjid Raya, Masjid Jami, Masjid Besar, berdasarkan data dari Sistem Informasi Masjid, Kementerian Agama Republik Indonesia (Kementerian Agama RI, 2019b). Sedangkan untuk fasilitas kuliner halal, pemerintah provinsi Sumatera Barat melakukan kerjasama dengan lembaga terkait untuk memberikan sertifikasi halal bagi produk UMKM maupun tempat makan. Maka dari itu dibuat kerjasama Pemerintah Provinsi Sumatera Barat dengan LPPOM MUI, Yayasan Minangkabau/Minangkabau World Foundation, dan Universitas Andalas, Padang (Majelis Ulama Indonesia, 2019a). Dinas Pariwisata Sumatera Barat merekomendasikan 22 rumah makan dan restoran tersertifikasi halal untuk memberikan layanan bagi wisatawan Muslim (Kompas.com, 2019b). Target rumah makan dan restoran yang tersertifikasi halal dapat mencapai 47 tempat (Republika.co.id, 2019). Tersedianya sertifikasi halal tentunya akan memberikan keyakinan bagi wisatawan Muslim dalam memenuhi konsumsinya.

Destinasi wisata halal Sumatera Barat yang dapat dikunjungi oleh wisatawan ada Danau Kembar yakni dua danau yang letaknya berdekatan berada di atas juga di bawah, lokasinya sekitar 47 kilometer dari Kabupaten Solok, jika dari Kota Padang sekitar 56 kilometer, Danau Kembar ini berlokasi di Kabupaten Solok, Kecamatan Lembayang Jaya, Desa Pasar Simpang; Pulau Cubudak kawasan ini bagian dari Mandeh di Pesisir Selatan, terdapat 13 bungalow untuk menginap dan untuk menuju ke sana dapat menggunakan motor boat, pengunjung dapat melakukan diving, snorkeling, maupun memancing di kawasan tersebut; Lembah Ani sebagai salah satu maskot kota Padang bahkan Sumatera Barat ini menyuguhkan keindahan panorama alam; Jembatan Siti Nurbaya, jembatan yang menghubungkan antara Kota Tua Padang dan Taman Siti Nurabaya diambil dari cerita populer Siti Nurbaya membentang sepanjang 260 meter; Pulau Sikuai dapat diakses melalui Dermaga Airud Bungus waktu tempuhnya mencapai 35 menit, pulau ini dekat dari Kota Padang sejauh 1,6 kilometer; dan tak lupa wisatawan dapat mengunjungi Danau Maninjau, keindahan danau ini ditempuh melalui Bukittinggi sekitar 36 kilometer; 140 kilometer dari Padang; 27 kilometer Lubuk Basung (Viva.co.id, 2016). Keindahan alam Sumatera 
Barat yang dapat dinikmati wisatawan Muslim memiliki keindahan dan keunikan tersendiri, mulai dari pegunungan hingga keindahan pantai.

Pariwisata halal Sumatera Barat mampu berbicara di dunia dengan tagline "Taste of Padang" dimaksudkan untuk memberikan pesan kepada masyarakat bukan hanya tentang merasakan cita rasa makanan, tetapi juga untuk merasakan berbagai pengalaman menarik di Sumatera Barat. Pada tahun 2016 pada kegiatan World Halal Tourism Award di Abu Dhabi mendapat penghargaan di tiga kategori yaitu kuliner, destinasi, dan operator wisata. Sumatera Barat dinobatakan sebagai World's Best Halal Tour Operator untuk Ero Tour, World's Best Halal Destination, dan World's Best Culinary Destination. (Republika.co.id, 2017a). Hal ini sangat memberikan dampak positif bagi citra pariwisata halal Sumatera Barat karena mendapatkan penghargaan internasional, peraturan daerah sedang dipersiapkan untuk mendukung penyelenggaraan pariwisata halal di Sumatera Barat.

\section{Diplomasi Pariwisata Halal Indonesia}

Industri halal menjadi salah satu instrumen dalam diplomasi ekonomi Indonesia karena menyadari potensi yang dimiliki. Hal ini disampaikan pada saat Penyampaian Prioritas Politik Luar Negeri Republik Indonesia 2019-2024 salah satunya penguatan ekonomi salah satunya dengan pembangunan industri halal. (Kementerian Luar Negeri RI, 2019a).

Kedatangan Raja Salman dari Arab Saudi sebagai endorser yang dapat memberikan dampak positif menarik pasar Timur Tengah. Terlebih Raja Salman memperpanjang masa liburannya saat berada di Indonesia (Kementerian Pariwisata RI, 2017). Hal ini sangat berarti bagi Indonesia karena orang nomor satu di Arab Saudi berkunjung tidak hanya sekedar urusan negara yang akhirnya menyepakati beberapa kerjasama, tetapi juga menikmati pariwisata Indonesia.

Sedangkan untuk promosi wisata halal di Malaysia, Indonesia mengikuti Malaysia International Halal Showcase (Mihas) 2019 untuk melakukan branding dan selling untuk mempromosikan wisata halal Indonesia prioritas dan ingin menunjukkan eksistensi pariwisata Indonesia di Asia Tenggara, terutama menyasar Malaysia sebagai target utama di ASEAN. Acara yang diselenggarakan pada 3 - 6 April 2019 di Malaysia International Trade \& Exhibition Centre (MITEC) (Kompas.com, 2019a).

Kementerian Pariwisata RI juga melakukan Familitrazion Trip (Famtrip) dengan mengajak rombongan agen wisata asal Timur Tengah berkunjung ke Lombok dan Bali yang dilaksanakan pada 11 hingga 18 April. Lombok menjadi tempat pertama yang dikunjungi dan menginap di Hotel Savarga, Lombok. Hari kedua menyebrang ke Gili Meno dan Gili Air yang kemudian menginap di Gili Trawangan, Jambuluwuk Resort. Setelah itu baru berangkat ke Bali untuk memperkenalkan tempat yang pernah dikunjungi Raja Salman (Republika.co.id, 2017b). Melakukan famtrip ke NTB dengan tema "Familiarization Trip for Ambassadors of Middle East Countries: Promoting Cooperation in the Field of Trade, Tourism and Investment". Para perwakilan negara berasal dari Mesir, Arab Saudi, Iraq, Oman, Yaman, Tunisia, Libya, Maroko, Bahrain, dan Qatar. Mereka diajak berkunjung ke berbagai destinasi wisata di Lombok, terutama Kawasan Ekonomi Khusus Mandalika yang sebagian kawasan tersebut dibuat khusus untuk kawasan wisata halal (PPID NTB, 2016).

Influencer dan jurnalis asal Timur Tengah juga diajak untuk mengikuti famtrip. Jurnalis asal Mesir dan influencer asal Arab Saudi berkunjung ke Malang, Bali dan Lombok dari 18 sampai 26 Oktober 2019 yang dibagi menjadi dua grup. Asal Arab Saudi ke Malang mengunjungi Batu Paragliding, Jatim Park 2, Kawasan Bromo, dan Air Terjun Madakaripura di Probolinggo. Sedangkan asal Mesir ke Lombok mengunjungi Gili Air, Gili Meno, Gili Trawangan, Air Tejun Benang Kelambu, Air Terjun Benang Stokel, Kuta Banyumulek pottery village, Kuta, Desa Sasak, dan Tanjung Aan. Kedua grup ini kemudian bertemu di Bali (Okezone.com, 2019). Harapannya influencer dan jurnalis ini mempromosikan keindahan 
destinasi wisata Indonesia, sehingga wisatawan asal Timur Tengah seperti Arab Saudi dan Mesir berkunjung ke Indonesia.

Sumatera Barat juga mempromosikan wisata halal ke Oman melalui Kedutaan Besar Republik Indonesia di Muscat melakukan kerjasama dengan Kementerian Pariwisata RI dan Pemerintah Provinsi Sumatera Barat, dan Association of Sales Travel Indonesia dengan cara mengundang agen perjalanan asal Oman dan jurnalis untuk menikmati destinasi wisata Sumatera Barat mulai tanggal 6 sampai 10 Oktober 2018 mengunjungi Ngarai Sianok, Isatana Pagaruyung, Bukittinggi, dan tentunya Kota Sawahlunto (Tempo.co, 2018).

Sedangkan Aceh melakukan famtrip juga dengan menyasar wisatawan asal Oman yang diselenggarakan berkat kerjasama Pemerintah Provinsi Aceh dengan KBRI Muscat, ASATI Aceh pada 22 hingga 26 Desember 2019 dengan mengundang lima agen travel, satu orang traveler, dan satu orang jurnalis. Mereka diajak berkunjung ke Masjid Al-Makmur merupakan bantuan pemerintah Oman saat Tsunami lalu, mengunjungi Masjid Baiturrahman, Pantai Lampu'uk, Rumah Adat Cut Nyak Dien, dan beberapa tempat lainnya. Selain berkunjung juga ada table-top meeting antara agen travel Aceh dan Oman untuk mengetahui potensi wisata Aceh (Kementerian Luar Negeri RI, 2019b).

Sama halnya dengan pangsa pasar Timur Tengah, Indonesia juga menyasar pasar Mediterania Timur yang meliputi Turki, Jordan, Suriah, Cyprus, Palestina, Mesir, Lebanon, dan Iraq. Menteri Pariwisata Arief Yahya pada acara Gala Dinner Indoleveant Travel Mart 2019 di W Hotel, Amman Yordania yang dihadiri oleh perwakilan berbagai negara dari Mediterania Timur. Dalam kesempatan tersebut Arief Yahya mengundang wisatawan Mediterania Timur untuk berkunjung ke Indonesia melalui Program Tourism Hub dari Thailand, Singapura, dan Malaysia yang kemudian melanjutkan perjalanan ke Indonesia (Kementerian Pariwisata RI, 2019b). Publikasi media elektronik untuk menyasar wisatawan Timur Tengah memasang iklan di media seperti Munhwa Broadcasting Corporation memasang di 30 spot, juga di Al Arabiya dengan 140 spot iklan.(Kementerian Pariwisata RI, 2018c).

Keberhasilan destination branding dan diplomasi publik Indonesia sebagai destinasi wisata halal dapat dilihat dari peringkat Indonesia menjadi peringkat pertama dengan nilai 78 sebagai destinasi wisata halal terbaik dunia berdasarkan Global Travel Index 2019 yang memperhatikan aksesibilitas, lingkungan, komunikasi dan layanan (MasterCard; CrescentRating, 2019). Pada tahun 2017 peringkat ketiga dengan nilai 72,6 (MasterCard; CrescentRating, 2017). Sedangkan tahun 2018 berada di peringkat kedua dengan nilai 72.8 (Mastercard \& CrescentRating, 2018). Ini menunjukkan kemajuan dalam pembangunan pariwisata halal di Indonesia.

Untuk Kunjungan dari Timur Tengah di dominasi oleh wisatawan asal Arab Saudi, Uni Emirat Arab, Mesir, Kuwait serta negara di kawasan Timur Tengah lainnya (Kementerian Pariwisata RI, 2018a). Pada Juni 2019 menunjukkan peningkatan sebanyak 36.000 wisatawan asal Timur Tengah ke Indonesia jika dibandingkan dengan bulan Mei 2019 hanya 5.800, ini mengalami peningkatan tinggi jika dibandingkan dengan bulan Juni 2018 yang hanya 26.500 orang (Republika.co.id, 2019). Proyeksi kunjungan wisatawan Muslim secara keseluruhan pada tahun 2019 mencapai 3,6 juta wisatawan, target selanjutnya pada tahun 2020 mencapai 4 juta wisatawan, 2021 mencapai 4,5 juta wisatawan, 2022 mencapai 5 juta wisatawan, 2023 mencapai 5,5 juta wisatawan, dan 2024 mencapai 6 juta wisatawan. (Bisnis.com, 2019). Target ini diharapkan mampu memberikan stimulus untuk lebih serius dalam pembangunan pariwisata halal Indonesia dan terutama yang menjadi destinasi unggulan.

\section{E. SIMPULAN}

Dalam pengembangan wisata halal dilakukan langkah strategis, yakni menetapkan logo dan tagline "Halal Tourism Indonesia: The Halal Wonders" untuk mengambarkan keindahan pariwisata

94 Jurnal Kepariwisataan: Destinasi, Hospitalitas dan Perjalanan, Volume 4 Nomor 2, 2020: 84-97 
Indonesia terutama pariwisata halal yang memiliki potensi yang baik. Sehingga layak untuk dikunjungi oleh wisatawan Muslim sebagai negara yang memiliki populasi terbesar di dunia. Strategi lain yang digunakan memilih tiga daerah dengan karakteristiknya masing-masing untuk mengembangkan wisata halal yakni Lombok dengan tagline "Friendly Lombok" sebagai gambaran bahwa Lombok ramah terhadap wisatawan yang berkunjung, Aceh dengan tagline "The Light of Aceh" untuk menunjukkan bahwa Aceh memiliki nuansa Islam yang dapat memberikan cahaya rahmatan lil alamin atau baik untuk semua, sedangkan Sumatera Barat dengan tagline "Taste of Padang" yang menawarkan pengalaman menarik dengan citarasa tersendiri. Setiap daerah ini memiliki peraturan terkait penyelenggaraan wisata halal.

Halal juga menjadi instrumen dalam melakukan diplomasi sesuai arah politik luar negeri Indonesia tahun 2019-2024. Indonesia juga memiliki undang-undang jaminan produk halal sebagai upaya memberikan jaminan untuk wisatawan Muslim bahwa yang dikonsumsinya halal. Selain itu juga melakukan promosi melalui event internasional, media, dan mengajak berbagai unsur dari luar negeri melalui familiarization trip seperti para duta besar, jurnalis, influencer, serta agen perjalanan wisata untuk berkunjung menikmati pariwisata halal dengan harapan dapat memberikan dampak pada kunjungan wisatawan Muslim ke Indonesia.

Strategi yang dilakukan cukup berhasil jika melihat dari peringkat internasional dari Global Muslim Travel Index menjadi nomor satu, serta wisatawan asal Timur Tengah mulai berdatangan dan menunjukkan peningkatan. Namun masih perlu banyak perbaikan pada beberapa hal seperti akses transportasi, keamanan, dan kenyamanan menjadi prioritas utama dalam keputusan berwisata. Sehingga target sebagai destinasi wisata halal dunia dengan kunjungan wisatawan Muslim terbanyak dapat tercapai sesuai dengan proyeksi yang diharapkan.

\section{DAFTAR REFERENSI}

Astuti, R. D. R. S. (2019). Pengembangan Pariwisata Halal di Indonesia. Collaborative Governance Dalam Pengembangan Pariwisata Di Indonesia, 01, 331-353.

Athoillah, N. A. (2019). Economic Development Through Halal Tourism. Munich Personal RePEc Archive, (94834).

Badan Pusat Statistik Indonesia. (2010). Kewarganegaraan, Suku Bangsa, Agama, dan Bahasa Sehari-Hari Penduduk Indonesia: Hasil Sensus 2010. Jakarta: Badan Pusat Statistik Indonesia.

Bisnis.com. (2019). Ini Jurus Kemenparekraf Jadikan Indonesia Destinasi Wisata Ramah Muslim Kelas Dunia.

BPS Provinsi NTB. (2017). Persentase Penduduk Menurut Kabupaten/Kota dan Agama yang Dianut di Provinsi Nusa Tenggara Barat 2016.

Cai, L. A. (2002). Cooperative branding for rural destinations. Annals of Tourism Research, 29(3), 720-742. https://doi.org/10.1016/S0160-7383(01)00080-9

CNBC Indonesia. (2019). Wisata Halal RI Kalah dari Malaysia, Ini Penyebabnya. Jakarta: CNBC Indonesia.

CNN Indonesia. (2015). Indonesia Raih Tiga Penghargaan Wisata Halal Dunia.

Dewan Masjid Indonesia. (2019). Aplikasi DMI Batu Kemenag Hitung Jumlah Masjid di Indonesia.

Dimitrios, B. (2000). Marketing the competitive destination of the future. Tourism Management, 21(1), 97-116.

Dinas Kebudayaan dan Pariwisata Aceh. (2016). Branding Baru "The Light Of Aceh."

Dinas Kebudayaan dan Pariwisata Aceh. (2018). Implementasi Halal Tourism Di Aceh Dinilai Sudah Bagus.

Genoveva, \& Muhammad, K. I. (2019). Analyzing the Perspective of Halal Tourism Development: City Branding in Jakarta. Proceedings of the International Conference on Trade 2019 (ICOT 2019), 98(Icot), 142-146. https://doi.org/10.2991/icot-19.2019.30 
Jan Melissen. (2005). The New Public Diplomacy Soft Power in International Relations. In Foreign Affairs. https://doi.org/10.2307/20050310

Kementerian Agama RI. (2019a). Daftar Profil Masjid di Provinsi Aceh.

Kementerian Agama RI. (2019b). Daftar Profil Masjid di Provinsi Sumatera Barat.

Kementerian Agama RI. (2019c). Data Masjid dan Data Mushalla.

Kementerian Luar Negeri RI. (2019a). Pidato Politik Luar Negeri Indonesia 2019-2024. In Kementerian Luar Negeri RI. Jakarta.

Kementerian Luar Negeri RI. (2019b). Tawarkan Wisata Halal, Pemprov Aceh Undang Wisatawan Oman melalui Famtrip.

Kementerian Pariwisata RI. (2016). Siaran Pers Menteri Pariwisata Berikan Penghargaan Anugerah Pariwisata Halal Terbaik 2016.

Kementerian Pariwisata RI. (2017). CEO Message \#21 Raja Salman dan Halal Tourism.

Kementerian Pariwisata RI. (2018a). Jumlah Kunjungan Wisatawan Mancanegara Ke Indonesia Tahun 2018. Jakarta.

Kementerian Pariwisata RI. Logo Halal Tourism Indonesia.pdf. , Pub. L. No. KM.40/UM.001/MP/2018, 8 (2018).

Kementerian Pariwisata RI. (2018c). Publikasi Media Elektronik Tahun 2018. Jakarta.

Kementerian Pariwisata RI. (2019a). Narasi Tunggal : 5 Tahun Kembangkan Pariwisata Halal, Indonesia Akhirnya Raih Peringkat Pertama Wisata Halal Dunia 2019.

Kementerian Pariwisata RI. (2019b). Siaran Pers : Menpar Undang Wisman Mediterania Timur Berkunjung ke Indonesia.

Kompas.com. (2019a). Di Mihas 2019, Kemenpar Promosikan Wisata Halal.

Kompas.com. (2019b). Wisata Halal Sumbar, Ini 22 Rumah Makan yang Direkomendasikan Dinas Pariwisata.

Leonard, M. C. S. C. S. (2002). Public Diplomacy. In Making Diplomacy Work: Intelligent Innovation for the Modern World. https://doi.org/10.4135/9781483395944.n7

LombokPostTV. (2016). Dialog Khusus LombokPostTV Bersama Kementerian Pariwisata RI, Dinas Pariwisata NTB, dan ASITA NTB. Mataram: LombokPostTV.

LPPOM MPU ACEH. (2019). Daftar Produk Bersertifikasi Halal LPPOM MPU Aceh.

LPPOM MUI NTB. (2016). Data Sertifikasi Halal Provinsi Nusa Tenggara Barat. Mataram.

Majelis Ulama Indonesia. (2017). MUI Bangun Aplikasi Berbasis QR Code Scanner.

Majelis Ulama Indonesia. (2019a). MWF Fasilitasi Sertifikasi Halal MUI untuk UKM Sumbar.

Majelis Ulama Indonesia. (2019b). Statistik Sertifikasi Halal MUI.

Mastercard; CrescentRating. (2015). Global Muslim Travel Index 2015. Singapore.

Mastercard; CrescentRating. (2017). Global Muslim Travel Index 2017. Singapore.

Mastercard; CrescentRating. (2019). Global Muslim Travel Index 2019. (April).

MasterCard; CrescentRating. (2016). Global Muslim Travel Index 2016. Singapore.

Mastercard, \& CrescentRating. (2018). Global Muslim Travel Index 2018. Singapore.

Millatina, A. N., Hakimi, F., Zaki, I., \& Yuningsih, I. (2019). Peran Pemerintah Untuk Menumbuhkan Potensi Pembangunan Pariwisata Halal Di Indonesia. Jurnal Manajemen Dan Bisnis Indonesia, 5(1), 96-109.

Okezone.com. (2019). Jurnalis Mesir \& Influencer Arab Nikmati Wisata Lombok, Malang dan Bali.

Organisasi Kerjasama Islam. (2017). Strategic Roadmap For Development of Islamic Tourism in OIC Member Countries. Ankara-Turkey.

Pew Research Center. (2019). The countries with the 10 largest Christian populations and the 10 largest Muslim populations.

PPID NTB. (2016). 10 Dubes Timur Tengah Sambangi NTB.

Pratama, A. H., Sulistiyanto, S., \& Ali, Y. (2019). the Effort of West Sumatra Province To Embrace Halal Tourism. The International Seminar Series on Regional Dynamics Proceeding, 223231. https://doi.org/10.19184/issrd.v1i1.13739

Presiden RI. (2019). Di Kompleks GBK, Resmikan Kawasan Ekosistem Industri Halal Indonesia.

Republika.co.id. (2017a). Raih Kemenangan di World Halal Tourism, Sumbar Tingkatkan Infrastruktur.

96 Jurnal Kepariwisataan: Destinasi, Hospitalitas dan Perjalanan, Volume 4 Nomor 2, 2020: 84-97 
Republika.co.id. (2017b). Rombongan Travel Agen Asal Timur Tengah Diajak Keliling BaliLombok.

Republika.co.id. (2019). Sumbar Targetkan 47 Restoran Bersertifikat Halal.

Risitano, M. (2006). The role of destination branding in the tourism stakeholders system. The Campi Flegrei case. IV International Doctoral Tourism and Leisure Colloquium, 1-18.

Ritchie, J. R. B., \& Ritchie, R. J. B. (1998). The Branding of Tourism Destinations: Past Achievements \& Future Challenges. Annual Congress of the International Association of Scientific Experts in Tourism, 98(September), 1-31.

SK Gubernur Sumatera Barat. Gubernur sumatera barat. , Pub. L. No. NOMOR : 14/Dispar-SK/III2018, 4 (2015).

Stăncioiu, A. F., Teodorescu, N., Pârgaru, I., Vlădoi, A. D., \& Băltescu, C. (2011). The Image of the Tourism Destination - a Supporting Element in the Development of the Regional Tourism Brand Study Case: Muntenia. Theoretical and Applied Economics, XVIII(2), 139-152.

Subarkah, A. R. (2018). Diplomasi Pariwisata Halal Nusa Tenggara Barat. Intermestic: Journal of International Studies, 2(2), 188. https://doi.org/10.24198/intermestic.v2n2.6

Susetyo, B. (2008). Peranan Diplomasi Publik. direktorat politik dan komunikasi kementerian ppn/bappenas.

Tempo.co. (2018). Sumatera Barat Tawarkan Wisata Halal kepada Turis Oman.

ThomsonReuters and DinarStandard. (2019). State of the Global Islamic Economy Report 2019/20. Abu Dhabi.

Travel.tempo.co. (2019). Melancong ke Tanah Rencong, Ini Dia Destinasi Halal di Aceh.

Viva.co.id. (2016). Sumatera Barat Punya 6 Tempat Wisata Halal Unggulan.

Wahyono, M. R. J. G. B. (2019). Atribut Wisata Halal sebagai Peningkatan Daya Saing Pariwisata. PROSIDING SEMINAR NASIONAL AKUNTANSI, MANAJEMEN, DAN KEUANGAN, 3-6. 